\title{
Modeling the Effectiveness of Employee Compensation Based on Financial Resources
}

\author{
L. B. Sungatullina ${ }^{1}$, E. I. Kadochnikova ${ }^{1} \&$ G. R. Faizrahmanova ${ }^{1}$ \\ ${ }^{1}$ Institute of Management, Economics and Finance, Department of Economics Theory and Econometrics, Kazan \\ Federal University, Kazan, Russia \\ Correspondence: E. I. Kadochnikova, PhD in Economics, Associate Professor at the Institute of Management, \\ Economics and Finance, Department of Economics Theory and Econometrics, Kazan Federal University, Kazan, \\ Russia.
}

Received: September 4, 2020

Accepted: October 10, 2020

Online Published: November 30, 2020

doi:10.5430/ijfr.v11n6p63

URL: https://doi.org/10.5430/ijfr.v11n6p63

\begin{abstract}
Modeling the effectiveness of employee compensation by evaluating the relationship with the factors of the labor intensity of products, work experience, and incentive payments based on a linear model of multiple regression on the main components. In this paper, several methods are utilized, including the classical least squares method, variation inflation factor, principal component method. It is expected with theoretical representations that the labor intensity of products reduces the efficiency of employee remuneration, the experience and incentive payments in the General Fund of remuneration positively contribute to the increase in the efficiency of employee remuneration. The expediency of applying linear regression to the main components for measuring internal corporate factors of the employee remuneration system is shown since the linear model of multiple regression can give incorrect estimates due to collinear regressors. A methodological way to modeling employee remuneration effectiveness based on a regression on individual determinants of the motivation and remuneration system has been developed. The developed methodological means to modeling employee remuneration effectiveness has been tested on a poultry enterprise's data for the period from January 2015 to March 2020. The article's main conclusions can be used in the scientific and practical activities of agricultural enterprises in measuring and evaluating the effectiveness of using financial resources to pay.
\end{abstract}

Keywords: pay, efficiency, salary return, economic analysis, linear regression model, principal component method

\section{Introduction}

Changing the model of economic development against the backdrop of the digitalization of economic processes poses challenges to the remuneration system, the solution of which is associated with an objective assessment of its effectiveness. It is important to solve the problems of consistency of the employee's remuneration system with the final results of the enterprise (Chingos, 2002). Addressing these issues requires improving approaches to modeling and evaluating the remuneration effectiveness, considering factors that affect both motivation and incentives for employees and their performance (Sungatullina et al., 2018). This approach will contribute to an objective assessment of the current remuneration system, considering the use of financial resources in the implementation of business goals (Sungatullina, Faizrahmanova, 2016). In this context, the main task of modeling is an integrated process that allows you to bring stable success to the enterprise. This process connects the goals of the enterprise and the experience and qualifications of employees. Besides, it connects different aspects of motivation with the development of the remuneration system to achieve a coordinated approach for solving economic problems. Furthermore, it permits to increase the level of competitiveness of the enterprise (Kulikova et al., 2016, Safiullin et al., 2018).

The main task of modeling and evaluating the effectiveness of remuneration is to achieve optimal performance of the enterprise and employees within a coherent system of business goals and objectives and requirements for the competence and productivity of employees (Boyd, Salamin, 2001). This approach is based on the principles of performance management, which allows one to align the tasks of the enterprise with the tasks of the employees, as well as measure the performance of the enterprise as a whole and each employee individually (Barrett, Mayson, 2007; Sheardwell, Claydon, 2010). Performance modeling is one of the management processes and is based on the "Plan - 
Do - Check - Act" model (Deming, 1986). This cycle includes the following processes: agreeing on goals at the planning stage; performing the work necessary to achieve the goals at the action stage; checking progress towards the goals at the monitoring stage; and discussing progress at the verification stage. One of the problems of modeling and evaluating the effectiveness of employee compensation is to ensure quality checks that allow one to formulate fair conclusions. This requires a continuous process rather than a single annual assessment. Besides, it is necessary to correctly approach the definition of factors that affect the change in the effectiveness of remuneration. This process is strategic, since it is related to the broad problems facing an enterprise that intends to function effectively in a competitive environment and achieve long-term goals in a certain direction. Thus, modeling the effectiveness of employee remuneration is one of the key stages in achieving strategic business goals based on a comprehensive approach to managing the system of motivation and remuneration.

In order to find the most appropriate model for evaluating the effectiveness of employee remuneration, we propose the construction of a simple linear multiple regression model and its extension based on the main components. This approach allows one not only to identify but also to measure factors that contribute to improving the efficiency of remuneration. The models are based on six quarterly financial indicators of the poultry enterprise for the period from 2015 to 2020. In this case, the usual least-squares method is used to evaluate model parameters, and the traditional formal Student and Fisher tests are used to verify statistical significance.

The chief purpose of this work is to recognize the determinants that contribute to the increase of the poultry enterprise's salary return.

The following results were obtained. An increase in the labor intensity of poultry products, the average salary of an agricultural worker and the proportion of such workers lead to a decrease in salary, an increase in the average length of service of agricultural workers and the share of additional incentive payments in the general salary fund leads to an increase in salary.

According to the formulated research questions, the paper describes the economic and financial indicators used and presents the results of evaluating the linear multiple regression models used. The conclusion contains conclusions and recommendations for further research in the field of analytical econometric tools determinants of employee pay efficiency.

\section{Research Question}

The need to model the effectiveness of employee remuneration raises the problem of choosing a specific model for its evaluation, as well as the selection of factors that affect the effectiveness of remuneration (Berndt, 1996). Modern information technologies allow one to use different methods of economic and mathematical research, taking into account business objectives and strategies for building a pay system. The idea of the study was suggested by works of (Berndt, 1996; Chingis, 2002).

Based on the literature, three main research questions were formulated:

1). Is there a connection between the efficiency of remuneration and the product's labor intensity?

2). Do incentive payments related to production results increase the efficiency of remuneration?

3). Does the experience of employees and their numbers affect the efficiency of remuneration?

\section{Research Methodology}

We are testing the proposed approach to modeling the efficiency of labor remuneration based on one of the Russian Federationpoultry enterprises' materials. To measure labor remuneration efficiency, we use the salary return indicator as to the ratio of labor costs to revenue from the sale of manufactured products. The data sample consists of six quarterly economic and financial indicators of the enterprise from January 2016 to December 2019, obtained from the official SPARK corporate information disclosure network (table 1): Y-salary, RUB.; X1 - the share of workers employed in poultry production, the total headcount of the enterprise, \%; X2 - the average salary per employee, RUB; X3 - average work experience per employee, years; X4 - the complexity of poultry production, hour/RUB; X5 - share of incentive payments related to production results in the total payroll, $\%$. 
Table 1. Descriptive statistics of variables

\begin{tabular}{lllllll}
\hline Variables & Average & Median & $\begin{array}{l}\text { Standard } \\
\text { deviation }\end{array}$ & Dispersion & Min & Max \\
\hline Salary return, rub. & 8,722 & 8,632 & 1,180 & 1,393 & 7,169 & 10,812 \\
\hline $\begin{array}{l}\text { The share of employees engaged } \\
\text { in poultry production in the total } \\
\text { number of employees of the } \\
\text { enterprise, \% }\end{array}$ & 66,966 & 66,6 & 1,125 & 1,266 & 65,240 & 68,740 \\
\hline $\begin{array}{l}\text { Average earnings per worker of } \\
\text { poultry production, rub. }\end{array}$ & 29435,760 & 29478,1 & 1335,587 & 1783793,0 & 26482,400 & 31452,300 \\
\hline $\begin{array}{l}\text { Average work experience of one } \\
\text { employee of poultry production, } \\
\text { years }\end{array}$ & 21,861 & 21,7 & 0,844 & 0,712 & 20,500 & 23,200 \\
\hline $\begin{array}{l}\text { Labor intensity of poultry } \\
\text { products, hour / RUB. }\end{array}$ & 0,116 & 0,121 & 0,157 & 0,025 & 0,095 & 0,141 \\
\hline $\begin{array}{l}\text { Share of incentive payments } \\
\text { related to production results in the } \\
\text { total remuneration fund,\%. }\end{array}$ & 14,720 & 14,65 & 1,162 & 1,349 & 12,820 & 17,730 \\
\hline
\end{tabular}

Using the classical method of least squares, we estimate the initial model of salary transfer. Let's determine the regression bloat criterion -VIF for each predictor. After that, implement the regression to the chief components to evaluate a multi-factor linear regression model's parameters. Comparing the original model quality estimates and regression on the central features is carried out utilizing student analyses and standard Fisher and for the standard model error. The simulation can be accomplished using the Gretl software package (Adkins, 2014).

In general, a linear multiple regression models can be represented as follows:

$$
Y_{t}=\beta_{0}+\beta_{1} x_{t 1}+\beta_{2} x_{t 2}+\beta_{m} x_{t 3}+\beta_{m} x_{t 4}+\beta_{m} x_{t 5}+\varepsilon_{t}
$$

Where $\mathrm{Yt}$ - salary return, rub.,

$\mathrm{Xt} 1$ - the share of employees engaged in poultry production in the overall number of staff of the enterprise, \%;

$\mathrm{Xt} 2$ - average earnings per worker of poultry production, rub.;

$\mathrm{Xt} 3$ - average work experience of one employee of poultry production, years;

Xt4 - Labor intensity of poultry products, hour / RUB.;

$\mathrm{Xt} 5$ - Share of incentive payments related to production results in the total remuneration fund, $\%$.

The advantages of regression models (Wooldridge, 2009; Hill, 2012) are the ability to: evaluate the contribution of each of the considered model factors to the final result - the variation of the explained variable; predict changes in the found dependencies in the future; enter the necessary correction, knowing the accuracy with which the result was obtained and direct actions based on data obtained with known accuracy; apply modern computer technologies.

To test the factors of the linear model of multiple regression for multicollinearity (Chandrasekhar et al., 2016; García et al., 2016; Salmerón Gómez et al., 2016, Yakupova et al., 2017), that is, the linear relationship with each other, we use the VIF criterion (variation inflation factor):

$$
V I F=\frac{1}{\left(1-R_{x j x 1 \ldots x j-1 x j+1 \ldots x m}^{2}\right)}
$$

Where $R_{x j 1 \ldots x j-1 x j+1 \ldots x m}^{2}$ - the determination coefficientfound for the equation of the dependent $\mathrm{Xj}$ variable from other 
variables $\mathrm{X} 1 \ldots \mathrm{Xm}$ included in the considered multiple regression model.

In order to preserve the collinear factors in the model, we estimate the regression on the chief components. The principal component method in multicollinearity conditions allows replacing highly related variables with new variables that do not correlate them. The new variables are linear compounds of the initial variables. The main intention of the principal component method is to replace the explanatory variables $x j, j=1,2, \ldots$ m with the principal components - the new variables $P C j, j=1,2, \ldots, k, k \leq m$, which are: first, free from the disadvantages caused by correlation dependence; second, they contain as much information as possible from the "old", original xj variables. The main components of the PCj are formed as linear compounds of the initial explanatory variables. The principal component method creates linear combinations of variables, decreasing the order of their impact on the first data's aggregate variance. That is to say; the first chief component is the linear combination of variables that owns the most considerable variance; the following element is the second-highest variance, etc. The maximum possible number of main components allocated is equal to the number of variables. The variances corresponding to the main components are called eigenvalues. According to the Kaiser criterion, the main components that have eigenvalues greater than 1 are allocated. In other words, if the component does not allocate a variance equivalent to the variance of a single variable, it is omitted. When selecting the main components, the main attention is paid to factor loads - correlations between standardized variables and selected components. To build a regression on the main components, z-standardization of the original XTi variables is performed, then the main components and their factor loads are determined using the newly obtained standardized ZTI variables. In the next step, the regression of the dependent variable $\mathrm{Yt}$ - payback on the main components are evaluated. Statistically insignificant main components are excluded from the regression equation, and the regression equation of the dependent variable with significant main components is obtained once again. Finally, the transition is made from the regression equation on the main components to the equation in the original XTi variables according to the transformation:

$$
\begin{aligned}
& \hat{y}_{t}=\beta_{0}+\beta_{1} l_{11} Z_{1}+\beta_{1} l_{12} Z_{2}+\beta_{1} l_{13} Z_{3}+\beta_{1} l_{14} Z_{4}+\beta_{1} l_{15} Z_{5}+\beta_{3} l_{31} Z_{1}+\beta_{3} l_{32} Z_{2}+\beta_{3} l_{33} Z_{3}++\beta_{3} l_{34} Z_{4}+\beta_{3} l_{35} Z_{5}+ \\
& +\beta_{5} l_{51} Z_{1}+\beta_{5} l_{52} Z_{2}+\beta_{5} l_{53} Z_{3}+\beta_{5} l_{54} Z_{4}+\beta_{5} l_{55} Z_{5}=\beta_{0}+\beta_{1} l_{11} \frac{x_{1}-\bar{x}_{1}}{\sigma_{x 1}}+\beta_{1} l_{12} \frac{x_{2}-\bar{x}_{2}}{\sigma_{x 2}}+\beta_{1} l_{13} \frac{x_{3}-\bar{x}_{3}}{\sigma_{x 3}}+ \\
& +\beta_{1} l_{14} \frac{x_{4}-\bar{x}_{4}}{\sigma_{x 4}}+\beta_{1} l_{15} \frac{x_{5}-\bar{x}_{5}}{\sigma_{x 5}}++\beta_{3} l_{31} \frac{x_{1}-\bar{x}_{1}}{\sigma_{x 1}}+\beta_{3} l_{32} \frac{x_{2}-\bar{x}_{2}}{\sigma_{x 2}}+\beta_{3} l_{33} \frac{x_{3}-\bar{x}_{3}}{\sigma_{x 3}}+\beta_{3} l_{34} \frac{x_{4}-\bar{x}_{4}}{\sigma_{x 4}}+\beta_{3} l_{35} \frac{x_{5}-\bar{x}_{5}}{\sigma_{x 5}}+ \\
& +\beta_{5} l_{51} \frac{x_{1}-\bar{x}_{1}}{\sigma_{x 1}}+\beta_{5} l_{52} \frac{x_{2}-\bar{x}_{2}}{\sigma_{x 2}}+\beta_{5} l_{53} \frac{x_{3}-\bar{x}_{3}}{\sigma_{x 3}}+\beta_{5} l_{54} \frac{x_{4}-\bar{x}_{4}}{\sigma_{x 4}}+\beta_{5} l_{55} \frac{x_{5}-\bar{x}_{5}}{\sigma_{x 5}}=\beta_{0}-\beta_{1} \frac{l_{11} \bar{x}_{1}}{\sigma_{x 1}}+\frac{l_{12} \bar{x}_{2}}{\sigma_{x 2}}+\frac{l_{13} \bar{x}_{3}}{\sigma_{x 3}}+ \\
& \left.+\frac{l_{14} \bar{x}_{4}}{\sigma_{x 4}}+\frac{l_{15} \bar{x}_{5}}{\sigma_{x 5}}\right)-\beta_{3}\left(\frac{l_{31} \bar{x}_{1}}{\sigma_{x 1}}+\frac{l_{32} \bar{x}_{2}}{\sigma_{x 2}}+\frac{l_{33} \bar{x}_{3}}{\sigma_{x 3}}+\frac{l_{34} \bar{x}_{4}}{\sigma_{x 4}}+\frac{l_{35} \bar{x}_{5}}{\sigma_{x 5}}\right)-\beta_{5}\left(\frac{l_{51} \bar{x}_{1}}{\sigma_{x 1}}+\frac{l_{52} \bar{x}_{2}}{\sigma_{x 2}}+\frac{l_{53} \bar{x}_{3}}{\sigma_{x 3}}+\frac{l_{54} \bar{x}_{4}}{\sigma_{x 4}}+\frac{l_{55} \bar{x}_{5}}{\sigma_{x 5}}\right)+ \\
& +x_{1}\left(\frac{\beta_{1} l_{11}}{\sigma_{x 1}}+\frac{\beta_{3} l_{31}}{\sigma_{x 1}}+\frac{\beta_{5} l_{51}}{\sigma_{x 1}}\right)+x_{2}\left(\frac{\beta_{1} l_{12}}{\sigma_{x 2}}+\frac{\beta_{3} l_{32}}{\sigma_{x 2}}+\frac{\beta_{5} l_{52}}{\sigma_{x 2}}\right)+x_{3}\left(\frac{\beta_{1} l_{13}}{\sigma_{x 3}}+\frac{\beta_{3} l_{33}}{\sigma_{x 3}}+\frac{\beta_{5} l_{53}}{\sigma_{x 3}}\right)+x_{4}\left(\frac{\beta_{1} l_{14}}{\sigma_{x 4}}+\frac{\beta_{3} l_{34}}{\sigma_{x 4}}+\frac{\beta_{5} l_{54}}{\sigma_{x 4}}\right)+ \\
& +x_{5}\left(\frac{\beta_{1} l_{15}}{\sigma_{x 5}}+\frac{\beta_{3} l_{35}}{\sigma_{x 5}}+\frac{\beta_{5} l_{55}}{\sigma_{x 5}}\right) \\
& b_{0} *=\beta_{0}-\beta_{1}\left(\frac{l_{11} \bar{x}_{1}}{\sigma_{x 1}}+\frac{l_{12} \bar{x}_{2}}{\sigma_{x 2}}+\frac{l_{13} \bar{x}_{3}}{\sigma_{x 3}}+\frac{l_{14} \bar{x}_{4}}{\sigma_{x 4}}+\frac{l_{15} \bar{x}_{5}}{\sigma_{x 5}}\right)-\beta_{3}\left(\frac{l_{31} \bar{x}_{1}}{\sigma_{x 1}}+\frac{l_{32} \bar{x}_{2}}{\sigma_{x 2}}+\frac{l_{33} \bar{x}_{3}}{\sigma_{x 3}}+\frac{l_{34} \bar{x}_{4}}{\sigma_{x 4}}+\frac{l_{35} \bar{x}_{5}}{\sigma_{x 5}}\right)- \\
& \beta_{5}\left(\frac{l_{51} \bar{x}_{1}}{\sigma_{x 1}}+\frac{l_{52} \bar{x}_{2}}{\sigma_{x 2}}+\frac{l_{53} \bar{x}_{3}}{\sigma_{x 3}}+\frac{l_{54} \bar{x}_{4}}{\sigma_{x 4}}+\frac{l_{55} \bar{x}_{5}}{\sigma_{x 5}}\right) \\
& b_{1}^{*}=\left(\frac{\beta_{1} l_{11}}{\sigma_{x 1}}+\frac{\beta_{3} l_{31}}{\sigma_{x 1}}+\frac{\beta_{5} l_{51}}{\sigma_{x 1}}\right) \\
& \mathrm{b}_{2} *=\left(\frac{\beta_{1} l_{12}}{\sigma_{x 2}}+\frac{\beta_{3} l_{32}}{\sigma_{x 2}}+\frac{\beta_{5} l_{52}}{\sigma_{x 2}}\right) \\
& \mathrm{b}_{3} *=\frac{\beta_{1} l_{13}}{\sigma_{x 3}}+\frac{\beta_{3} l_{33}}{\sigma_{x 3}}+\frac{\beta_{5} l_{53}}{\sigma_{x 3}} \\
& b_{4} *=\frac{\beta_{1} l_{14}}{\sigma_{x 4}}+\frac{\beta_{3} l_{34}}{\sigma_{x 4}}+\frac{\beta_{5} l_{54}}{\sigma_{x 4}} \\
& b_{5} *=\frac{\beta_{1} l_{15}}{\sigma_{x 5}}+\frac{\beta_{3} l_{35}}{\sigma_{x 5}}+\frac{\beta_{5} l_{55}}{\sigma_{x 5}} \\
& \hat{y}_{t}=a^{*}+b_{1}{ }^{*} \cdot x_{t 1}+b_{2}{ }^{*} \cdot x_{t 2}+b_{3}{ }^{*} \cdot x_{t 3}+b_{4}{ }^{*} \cdot x_{t 4}+b_{5}{ }^{*} \cdot x_{t 5} \text {. }
\end{aligned}
$$


To check whether the final model matches the actual data, we will determine the average approximation error:

$$
\bar{A}=\frac{1}{n} \sum\left|\frac{y_{t}-\hat{y}}{y_{t}}\right| \cdot 100 \% .
$$

\section{Results \& Discussion}

The investigation of linear coefficients of regressors pair correlation with a dependent variable (Ryxj) - Table 2, revealed that salary return holds a solid connection with the average salary of one employee of poultry production $($ Ryx $2=0.817)$, the average work experience of one employee of poultry production (Ryx $3=0.829)$, a close inverse connection with the labor intensity of poultry production $(\mathrm{Ryx} 4=-0.886)$. Regressor X5 - the share of incentive payments related to production results in the general fund of remuneration has a weak line (Ryx $5=0.210)$, and regressor X1 - the share of employees engaged in poultry production in the total number of employees of the enterprise $(\operatorname{Ryx} 1=-0.179)$ - a weak inverse connection to salary. However, the linear inter-factor correlation coefficients (Rxixj) in Table 1 show that there is a close connection (collinearity) between the predictors: $\mathrm{Rx} 2 \times 3=$ 0,$764 ; \mathrm{R} \times 2 \times 4=-0,899 ; \mathrm{R} \times 3 \times 4=-0,858$.

Correlation coefficients, utilizing the observations $1-21$

$5 \%$ critical value (two-tailed) $=0.4329$ for $\mathrm{n}=21$

Table 2. Matrix of correlation linear coefficients

\begin{tabular}{|c|c|c|c|c|c|}
\hline $\mathrm{Y}$ & $\mathrm{x} 1$ & $\mathrm{x} 2$ & $\mathrm{x} 3$ & $\mathrm{x} 4$ & \\
\hline \multirow[t]{12}{*}{1.0000} & -0.1789 & 0.8173 & 0.8289 & -0.8863 & $\mathrm{Y}$ \\
\hline & 1.0000 & 0.1621 & -0.2377 & 0.0993 & $\mathrm{x} 1$ \\
\hline & & 1.0000 & 0.7641 & -0.8987 & $\mathrm{x} 2$ \\
\hline & & & 1.0000 & -0.8576 & x3 \\
\hline & & & & 1.0000 & $\mathrm{x} 4$ \\
\hline & & & & $\times 5$ & \\
\hline & & & & 0.2101 & $\mathrm{Y}$ \\
\hline & & & & 0.0255 & $\mathrm{x} 1$ \\
\hline & & & & 0.0482 & $\mathrm{x} 2$ \\
\hline & & & & -0.0866 & $\mathrm{x} 3$ \\
\hline & & & & 0.1058 & $\mathrm{x} 4$ \\
\hline & & & & 1.0000 & $\mathrm{x} 5$ \\
\hline
\end{tabular}

For the purpose of analytical reflection of the statistical connection of salary return to a full set of factors, we perform an estimation of multi-factor regression using the classical least squares method (Table 3).

Model 1: OLS, applying considerations 1-21

Dependent variable: $\mathrm{Y}$ 
Table 3. OLS-estimates of multivariate payroll regression on a full range of factors

\begin{tabular}{llllll}
\hline & Coefficient & Std. Error & t-ratio & p-value & \\
\hline const & 8.62292 & 10.179 & 0.8471 & 0.41023 & \\
\hline $\mathrm{x} 1$ & -0.0492822 & 0.115262 & -0.4276 & 0.67504 & \\
\hline $\mathrm{x} 2$ & $-5.13751 \mathrm{e}-05$ & 0.000222709 & -0.2307 & 0.82068 & \\
\hline $\mathrm{x} 3$ & 0.316682 & 0.23692 & 1.3367 & 0.20125 & \\
\hline $\mathrm{x} 4$ & -58.1743 & 19.9251 & -2.9197 & 0.01056 & $* *$ \\
\hline $\mathrm{x} 5$ & 0.320641 & 0.0908115 & 3.5308 & 0.00303 & $* * *$ \\
\hline
\end{tabular}

Table 4. The results of testing model 1 for multicollinearity by the variance inflation factor method

\begin{tabular}{lcll}
\hline average dependent var & 8.722095 & S.D. dependent var & 1.180477 \\
\hline Total squared resid & 2.783688 & S.E. of regression & 0.430789 \\
\hline R-squared & 0.900121 & Adjusted R-squared & 0.866828 \\
\hline F(5, 15) & 27.03624 & P-value(F) & $5.31 \mathrm{e}-07$ \\
\hline Log-likelihood & -8.579877 & Akaike criterion & 29.15975 \\
\hline Schwarz criterion & 35.42689 & Hannan-Quinn & 30.51988 \\
\hline
\end{tabular}

Let's write down the original model of salary return:

$$
\boldsymbol{Y}_{\boldsymbol{t}}=8.62-0.05 \boldsymbol{X}_{\boldsymbol{t} 1}-0.0000514 \boldsymbol{X}_{t 2}+0.32 \boldsymbol{X}_{t 3}-58.17 \boldsymbol{X}_{t 4}+0.32 \boldsymbol{X}_{t 5}+\boldsymbol{E}_{\boldsymbol{t}} .
$$

As can be seen from Figure 2, the regression owns a determination coefficient - when R-square approaches 1, regression is important overall due to Fisher-test $(\mathrm{P}$-value $(\mathrm{F})<0,01)$ and with the coefficients of Student test regression when regressors $\mathrm{X} 1$ - the proportion of workers employed in poultry production, the total headcount of the enterprise, $\mathrm{X} 2$, - average salary per employee of poultry production, $\mathrm{X} 3$ - average work experience per employee poultry of production, are not significant. This position occurred due to the multicollinearity of predictors. The adverse outcomes of multicollinearity are an inexact linear correlation of regressor's coefficients with a dependent variable-payback, a reduction in the precision of evaluations of regression coefficients, and mistaken operation of the Student's test while examining the importance of a particular coefficient in the regressor. To recognize multicollinearity, we apply the calculation of the regression bloat criterion (Table 3).

Variance Inflation Factors

Minimum possible value $=1.0$

Values $>10.0$ can demonstrate a collinearity problem

$\mathrm{x} 1: 1.812$

$\mathrm{x} 2: 9.535$

$\mathrm{x} 3: 4.310$

$\mathrm{x} 4: 10.530$

x5: 1.199

$$
\operatorname{VIF}(j)=1 /\left(1-R(j)^{\wedge} 2\right)
$$

Where $R(j)$ is the multiple correlation coefficient between variable $j$ and the other independent variables

The presence of collinearity for the predictor X4 - labor intensity of poultry products was detected. It is possible to exclude correlating regressors in order to eliminate duplication of information. In Gretl, we perform a procedure for sequentially excluding redundant variables $(\mathrm{X} 1, \mathrm{X} 2, \mathrm{X} 3)$ using a two-way p-value $=0.05$ (Table 3 ).

Model 2: OLS, using observations 1-21

Dependent variable: $\mathrm{Y}$ 
Table 5. OLS estimates of multivariate payroll regression after eliminating omit variables

\begin{tabular}{llllll}
\hline & Coefficient & Std. Error & t-ratio & p-value & \\
\hline const & 12.1253 & 1.36318 & 8.8949 & $<0.00001$ & $* * *$ \\
\hline $\mathrm{x} 4$ & -69.142 & 6.20432 & -11.1442 & $<0.00001$ & $* * *$ \\
\hline $\mathrm{x} 5$ & 0.31232 & 0.0837898 & 3.7274 & 0.00154 & $* * *$ \\
\hline
\end{tabular}

Table 6. Principal component estimates

\begin{tabular}{lrll}
\hline Mean dependent var & 8.722095 & S.D. dependent var & 1.180477 \\
\hline Sum squared resid & 3.372375 & S.E. of regression & 0.432844 \\
\hline R-squared & 0.878998 & Adjusted R-squared & 0.865554 \\
\hline F(2, 18) & 65.37919 & P-value(F) & $5.56 \mathrm{e}-09$ \\
\hline Log-likelihood & -10.59421 & Akaike criterion & 27.18841 \\
\hline Schwarz criterion & 30.32198 & Hannan-Quinn & 27.86848 \\
\hline
\end{tabular}

Let us define the salary return model after eliminating redundant variables:

$$
\boldsymbol{Y}_{\boldsymbol{t}}=12.13-69.14 \boldsymbol{X}_{\boldsymbol{t} 4}+0.31 \boldsymbol{X}_{\boldsymbol{t}}+\boldsymbol{E}_{\boldsymbol{t}}
$$

As we can see from Figure 4, the regression has a coefficient of determination - R-square, close to 1, the regression is significant due to the Fisher test $(\mathrm{P}$-value $(\mathrm{F})<0.01)$, all regression coefficients are significant due to the Student's test.

In order to answer the research question, keep the factors in the model, as well as to obtain the best predictive characteristics and maintain the reliability and informativeness of the simulation, let us perform a regression on the main components. Z-standardization of variables and evaluate the main components was applied (Table 4).

Principal Component Analysis, $\mathrm{n}=21$

Eigenanalysis of the Correlation Matrix

\begin{tabular}{llll}
\hline Component & Eigenvalue & Proportion & Cumulative \\
\hline 1 & 2.4476 & 0.5194 & 0.5194 \\
\hline 2 & 1.1055 & 0.2346 & 0.7540 \\
\hline 3 & 0.9816 & 0.2083 & 0.9623 \\
\hline 4 & 0.1245 & 0.0264 & 0.9887 \\
\hline 5 & 0.0533 & 0.0113 & 1.0000 \\
\hline
\end{tabular}

Eigenvectors (component loadings)

\begin{tabular}{llllll}
\hline & PC1 & PC2 & PC3 & PC4 & PC5 \\
\hline Z1 & 0.045 & 0.833 & -0.473 & 0.225 & 0.171 \\
\hline Z2 & -0.601 & 0.262 & -0.005 & -0.357 & -0.665 \\
\hline Z3 & -0.492 & -0.149 & 0.070 & 0.852 & -0.072 \\
\hline Z4 & 0.626 & 0.037 & 0.012 & 0.307 & -0.716 \\
\hline Z5 & 0.051 & 0.462 & 0.878 & 0.047 & 0.104 \\
\hline
\end{tabular}

The initial and following chief elements own values higher than 1 and explain $51.9 \%$ and $23.5 \%$ of the dependent variable variance, in turn. The third, fourth, and fifth components have values less than 1 and explain together $24.6 \%$ of the dependent variable variance.

Factor loads on elements are the pair correlation coefficients, for the initial component - smaller than 0.7 for the entire variables, for the second component - more than 0.7 for the $\mathrm{Z} 1$ variable, for the third component - more than 0.7 for the Z5 variable, for the fourth component - more than 0.7 for the $\mathrm{Z} 3$ variable, for the fifth component - more 
than 0.7 (module) for the $\mathrm{Z} 4$ variable.

In the following procedures, we use the first, third, and fifth components defining regression equations using z-standardized variables:

$$
\begin{aligned}
\mathbf{P C}_{\mathbf{1}} & =0.045 \mathbf{Z}_{\mathbf{1}}-0.601 \mathbf{Z}_{\mathbf{2}}-0.492 \mathbf{Z}_{3}+0.626 \mathbf{Z}_{\mathbf{4}}+0.051 \mathbf{Z}_{5} . \\
\mathbf{P C}_{\mathbf{3}} & =-0.473 \quad \mathbf{Z}_{\mathbf{1}}-0.005 \mathbf{Z}_{\mathbf{2}}+0.070 \mathbf{Z}_{\mathbf{3}}+0.012 \quad \mathbf{Z}_{\mathbf{4}}-0.878 \mathbf{Z}_{\mathbf{5}} . \\
\mathbf{P C}_{5} & =0.171 \mathbf{Z}_{\mathbf{1}}-0.665 \mathbf{Z}_{\mathbf{2}}-0.072 \mathbf{Z}_{\mathbf{3}}-0.716 \mathbf{Z}_{\mathbf{4}}+0.104 \mathbf{Z}_{5} .
\end{aligned}
$$

Let's perform a regression of the salary return on all the main components (Table 5):

$$
\mathrm{Y}=8.72-0.64 \mathbf{P C}_{1}+0.03 \mathbf{P C}_{2}+0.36 \mathbf{P C}_{\mathbf{3}}-0.02 \quad \mathbf{P C}_{\mathbf{4}}+0.71 \mathbf{P C}_{5}+\mathrm{E} \text {. }
$$

Model 3: OLS, utilizing measurements 1-21

Dependent variable: $\mathrm{Y}$

Table 7. OLS estimates payroll regression results for principal components

\begin{tabular}{llllll}
\hline & Coefficient & Std. Error & t-ratio & p-value & \\
\hline const & 8.7221 & 0.0940059 & 92.7825 & $<0.00001$ & $* * *$ \\
\hline PC1 & -0.644957 & 0.0619291 & -10.4145 & $<0.00001$ & $* * *$ \\
\hline PC2 & 0.0341101 & 0.0914616 & 0.3729 & 0.71441 & \\
\hline PC3 & 0.361479 & 0.097188 & 3.7194 & 0.00206 & $* * *$ \\
\hline PC4 & -0.0228877 & 0.2422 & -0.0945 & 0.92596 & \\
\hline PC5 & 0.708912 & 0.416909 & 1.7004 & 0.10969 & \\
\hline
\end{tabular}

\begin{tabular}{lcll}
\hline average dependent var & 8.722095 & S.D. dependent var & 1.180477 \\
\hline Total squared resid & 2.783688 & S.E. of regression & 0.430789 \\
\hline R-squared & 0.900121 & Adjusted R-squared & 0.866828 \\
\hline F(2. 18) & 27.03624 & P-value(F) & $5.31 \mathrm{e}-07$ \\
\hline Log-likelihood & -8.579877 & Akaike criterion & 29.15975 \\
\hline Schwarz criterion & 35.42689 & Hannan-Quinn & 30.51988 \\
\hline
\end{tabular}

As can be seen from Figure 6, the regression has a coefficient of determination-R-square, close to 1; the regression is important due to Fisher's test (P-value $(\mathrm{F})<00.01)$, as well as for the Student's test, the regression coefficients for PC2 and PC4 are not significant.

We improved the model by performing a Gretl procedure for sequentially excluding redundant variables (PC2 PC4) utilizing a two-way p-value $=0.05$ (Table 8$)$ :

$$
\mathrm{Y}=8.722-0.643 \mathrm{PC}_{1}+0.361 \mathrm{PC}_{3}+0.711 \mathbf{P C}_{5}+\mathrm{E} \text {. }
$$

Model 4: OLS, utilizing observations 1-21

Dependent variable: $\mathrm{Y}$

Table 8. OLS estimates payroll regression results for principal components after eliminating omit variables

\begin{tabular}{llllll}
\hline & Coefficient & Std. Error & t-ratio & p-value & \\
\hline const & 8,7221 & 0,0887534 & 98,2733 & $<0,00001$ & $* * *$ \\
\hline PC1 & $-0,642545$ & 0,0556957 & $-11,5367$ & $<0,00001$ & $* * *$ \\
\hline PC3 & 0,361071 & 0,0917165 & 3,9368 & 0,00106 & $* * *$ \\
\hline PC5 & 0,711244 & 0,393498 & 1,8075 & 0,08841 & $*$ \\
\hline
\end{tabular}




\begin{tabular}{lcll}
\hline average dependent var & 8,722095 & S.D. dependent var & 1,180477 \\
\hline Total squared resid & 2,812150 & S.E. of regression & 0,406719 \\
\hline R-squared & 0,899099 & Adjusted R-squared & 0,881293 \\
\hline $\mathrm{F}(2,18)$ & 50,49423 & P-value(F) & $1,12 \mathrm{e}-08$ \\
\hline Log-likelihood & $-8,686692$ & Akaike criterion & 25,37338 \\
\hline Schwarz criterion & 29,55147 & Hannan-Quinn & 26,28014 \\
\hline
\end{tabular}

However, the description of the model in relation to the chief elements is difficult. Therefore, it is advisable to switch to a model containing initial factors that can be interpreted economically:

$$
\begin{gathered}
Y=8.722-0.643 *\left(0.045 \mathbf{Z}_{\mathbf{1}}-0.601 \mathbf{Z}_{2}-0.492 \mathbf{Z}_{3}+0.626 \mathbf{Z}_{\mathbf{4}}+0.051 \mathbf{Z}_{5}\right)+0.361 *\left(-0.473 \mathbf{Z}_{\mathbf{1}}-0.005 \mathbf{Z}_{\mathbf{2}}+0.070 \mathbf{Z}_{3}+\right. \\
\left.0.012 \mathbf{Z}_{\mathbf{4}^{-}}-0.878 \mathbf{Z}_{\mathbf{5}}\right)+0.711 *\left(0.171 \mathbf{Z}_{\mathbf{1}}-0.665 \mathbf{Z}_{\mathbf{2}}-0.072 \mathbf{Z}_{\mathbf{3}}-0.716 \mathbf{Z}_{\mathbf{4}}+0.104 \mathbf{Z}_{\mathbf{5}}\right)+\mathrm{E} .
\end{gathered}
$$

With

$\boldsymbol{\beta}_{\mathbf{0}}=8.72 ; \boldsymbol{\beta}_{\mathbf{1}}=-0.642 ; \boldsymbol{\beta}_{3}=0.361 ; \boldsymbol{\beta}_{\mathbf{5}}=0.711 ; \mathbf{L}_{\mathbf{1 1}}=0.045 ; \mathbf{L}_{\mathbf{1 2}}=-0.601 ; \mathbf{L}_{\mathbf{1 3}}=-0.492 ; \mathbf{L}_{\mathbf{1 4}}=0.626 ; \mathbf{L}_{15}=0.051 ; \mathbf{L}_{\mathbf{3 1}}=$ $-0.473 ; \mathbf{L}_{32}=-0.005 ; \mathbf{L}_{33}=0.070 ; \mathbf{L}_{34}=0.012 ; \mathbf{L}_{35}=0.878 ; \mathbf{L}_{51}=0.171 ; \mathbf{L}_{\mathbf{5 2}}=-0.665 ; \mathbf{L}_{\mathbf{5 3}}=-0.072 ; \mathbf{L}_{\mathbf{5 4}}=-0.716$; $\mathbf{L}_{55}=0.104$

We will get the final multi-factor regression model of salary return:

$$
\mathrm{Y}=9.849-0.069 \mathrm{x}_{1}-0.0000665 \mathrm{x}_{2}+0.344 \mathrm{x}_{3}-5.667 \mathrm{x}_{4}+0.308 \mathrm{x}_{5}+\mathrm{e} .
$$

According to the model (13), an increase in the share of employees engaged in poultry production in the total number of employees of the enterprise by $1 \%$ leads to a decrease in salary return by 0.069 rub. An increase in the average salary per employee of poultry production by 1 rub leads to a decrease in salary return by 0.0000665 rubs. An increase in the average work experience of one employee of poultry production for 1 year leads to an increase in salaries by 0.344 rubles. Increasing the labor intensity of poultry products by 1 hour / rub leads to a decrease in salary payments by 5.667 rubles, and an increase in the share of incentive payments related to production results in the general fund by $1 \%$ leads to an increase in salary payments by 0.308 rubles.

The average approximation error for checking whether the model (13) matches the actual data was 3.272\%. An approximation error of 5-7\% shows a good agreement of the model to the source data. The resulting value does not exceed $12-15 \%$, which indicates that the average deviation of the calculated data from the actual data used in the econometric model is insignificant and that the acceptable quality of the model selection is not significant.

\section{Conclusions and Future Research}

This survey is aimed at the methodological features of modeling the employee remuneration effectiveness in the enterprise management system, given a linear model of multiple regressions. The research is built on empirically verified theoretical arguments concerning increasing the remuneration efficiency to implement strategic business objectives (Armstrong, Murlis, 2004; Beardwell, Claydon, 2010; White, 2005). The findings are based on practical recommendations (Sungatullina et al., 2010; Berrocal et al., 2018; Bush, 2003; Sum, 2010), on methodological approaches of evaluating employee remuneration effectiveness, a motivating factor in the company's activities. The study's approach to modeling the salary efficiency has several benefits because of the ability to trace the factors connections representing employees' incentive system and experience. In particular, achieve a better selection of the remuneration system's predictive factors for an essential interpretation of the consequences of modeling in making management decisions. Hence, the study reinforces the standard assumptions about a statistically meaningful connection between individual factors (labor intensity, work experience, average salary, number of employees, incentive payments related to production results) that influence the system of motivation and incentives for employees' effectiveness of remuneration. All this serves to optimize the remuneration system and promote the efficiency of applying the company's resources. Advancing this study in the direction of studying a more extensive set of circumstances that affect the level of efficiency of employee remuneration permits one to develop the rational use of financial resources that relate to the business strategy.

\section{Acknowledgements}

The survey is conducted based on the Russian Government Program of Competitive Growth of Kazan University.

\section{References}

Adkins, L. C. (2014). Using gretl for principles of econometrics (4th ed.). Oklahoma State University Publisher, Oklahoma City, Oklahoma.

Armstrong, M., \& Murlis, H. (2004). Rewerd management (5th ed.). Kogan Page, London. 
Barrett, R., \& Mayson, S. (2007). Human resource management in growing small firms. Journal of Small Business and Enterprise Development, 14(2), 307-320. https://doi.org/10.1108/14626000710746727

Beardwell, J., \& Claydon, T. (2010). Human resource management: A contemporary approach. Pearson Education, London.

Berndt, E. R. (1996). The practice of econometrics: classic and contemporary. Ernst R. Berndt-Reading: Addison-Wesley Publishing Company, 18, 702.

Berrocal, F. B., Garcia, M. A. A., \& Ramirez-Vielma, R. (2018). Influence of the Type of Method on the Results of Job Evaluation. UCJC Business and Society Review, Tercer Trimestre.

Boyd, B. K., \& Salamin, A. (2001). Strategic reward systems: A contingency model of pay system design. Strategic Management Journal, 22(8), 777-792. https://doi.org/10.1002/smj.170

Bush, T. J. (2003). Leverage employee rewards to drive performance. Hoosier Banker, 87(4), 26-29.

Chandrasekhar, C. K., Bagyalakshmi, H., Srinivasan, M. R., \& Gallo, M. (2016). Partial ridge regression under $\begin{array}{lllll}\text { multicollinearity. Journal of Applied } & \text { Statistics, } & 43(13), & \text { 2462-2473. }\end{array}$ https://doi.org/10.1080/02664763.2016.1181726

Chingos, P. T. (2002). Paying for performance: a guide to compensation management (2nd ed.). Wiley.

Deming, W. E. (1986). Out of the Crisis. Massachusetts Institute of Technology Centre for Advanced Engineering Studies, Cambridge MA.

García, J., Salmerón, R., García, C., \& López Martín, M. D. M. (2016). Standardization of Variables and Collinearity Diagnostic in Ridge Regression. International Statistical Review, 84(2), 245-266.

Hill, R. C., Griffiths, W. E., \& Lim, G. C. (2012). Principles of Econometrics, International Student Version (4th ed., p. 792). John Wiley and Sons, Singapore.

Kulikova, L. I., Vetoshkina, E. Y., \& Nurgatin, R. R. (2016). Universal business activity level highlites in the financial management system. Academy of Strategic Management Journal, 15(Special Issue1), 114-121.

Safiullin, A. R., Khairullina, A., \& Sabirova, A. I. (2018). The effect of competition on the sustainable growth of the regional food market. Journal of Social Sciences Research, (Special Issue 5), 439-443.

Salmerón, G. R., García Pérez, J., López Martín, M. D. M., \& García, C. G. (2016). Collinearity diagnostic applied in ridge estimation through the variance inflation factor. Journal of Applied Statistics, 43(10), 1831-1849.

Sum, V. (2010). The role of training and firm's competitiveness in the knowledge-based economy. Review of Business and Technology Research, 3(1), 1-12.

Sungatullina, L. B., \& Faizrahmanova, G. R. (2016). The modeling of industrial entity's dynamics staff costs. Academy of Strategic Management Journal, 15, 69-76.

Sungatullina, L. B., Neizvestnaya, D. V., \& Kadochnikova, E. I. (2018). The efficiency analysis of measures to boost the labor productivity. Journal of Social Sciences Research, (Special Issue 1), 260-266.

Sungatullina, L. B., Sokolov, A. Y., Yankovskaya, D. G., Elsukova, T. V., \& Kadochnikova, E. I. (2018). Ways of performance improvement in petrochemical enterprise. Journal of Social Sciences Research, (Special Issue 5), 345-349. https://doi.org/10.32861/jssr.spi5.345.349

White, R. (2005). A strategic approach to building a consistent global rewards program. Compensation and Benefits Review, 23-39. https://doi.org/10.1177/0886368705278061

Wooldridge, M. (2009). Introductory Econometrics: A Modern Approach (p. 865).

Yakupova, N. M., Kvon, G. M., Salahieva, M. F., Kadochnikova, E. I., \& Lelyukh, A. V. (2017). Peculiarities of modelling of the enterprise investment attractiveness in the conditions of multicollinearity of predictors. Journal of Engineering and Applied Sciences, 12(19), 4922-4926.

\section{Copyrights}

Copyright for this article is retained by the author(s), with first publication rights granted to the journal.

This is an open-access article distributed under the terms and conditions of the Creative Commons Attribution license (http://creativecommons.org/licenses/by/4.0/). 